Journal of Mathematics and Informatics

Vol. 18, 2020, 145-156

ISSN: 2349-0632 (P), 2349-0640 (online)

Published 22 June 2020

www.researchmathsci.org

DOI: http://dx.doi.org/10.22457/jmi.v18a13173

Journal of

Mathematics and

Informatics

\title{
Numerical Investigation of the Effect of Parameters in Nanofluid Flows in a Channel with Navier Slip and Convective Cooling
}

\author{
Issa Shaban Mfinanga \\ Department of Mathematics, Informatics and Computational Sciences \\ College of Science and Education, Sokoine University of Agriculture \\ Morogoro - Tanzania \\ Email: mfinangaissa1@gmail.com
}

Received 12 May 2020; accepted 20 June 2020

\begin{abstract}
This study aimed to investigate on the effect of parameters in nanofluid flows in a Channel with Navier Slip and Convective Cooling.The nanofluid in a channel modal was developed for determining the effect of different parameter on velocity and temperature of nanofluid and to determine the effect of Navier slip. The appropriate mathematical model for the problem was derived from the laws of conservation, momentum and energy balance where both first and second laws of thermodynamics are utilized to analyze the model problem. Using discretization finite difference method together with Runge-Kutta Fehlberg integration scheme implemented on the Computer using Matlab software, the governing partial differential equations was solved numerically.

The Alumina $\left(\mathrm{Al}_{2} \mathrm{O}_{3}\right)$ and Copper $(\mathrm{Cu})$ nanoparticles was used to formulate water based nanofluid. The findings showed that for both Alumina-water and $\mathrm{Cu}$-water nanofluids velocity increases with time until it reaches their steady state, but Aluminawater reaches its steady state earlier than $\mathrm{Cu}$-water. The nanofluid velocity increases with Reynolds number (Re), pressure gradient, (A) but decreases with an increase in nanoparticle volume fraction $\phi$. The nanofluid temperature increases with Eckert number $(\mathrm{Ec})$, but decrease with an increase in Biot number (Bi) and nanoparticle volume fraction $(\phi)$.
\end{abstract}

Keywords: Channel; Parameters; Nanofluid; Navier Slip; Convective Cooling.

AMS Mathematics Subject Classification (2010): 82D80

\section{Introduction}

Nanofluids is formed when nanoparticles is suspended in a base fluid, typically water. Materials used as nanoparticles includes; Oxides ceramics- $\mathrm{Al}_{2} \mathrm{O}_{3}, \mathrm{CuO}-\mathrm{Metal}$ carbides, Sic Nitrides- AlN, SiN Metals, Al, Cu Metals, Non Metals- Graphite, Carbon nanotubes Layered- $\mathrm{Al}+\mathrm{Al}_{2} \mathrm{O}_{3}, \mathrm{Cu}+\mathrm{C}$ Base fluids includes; Water ethylene-or tri-ethylene-glycols and other coolants oil and other Lubricants Bio-fluids and Polymer solution. The figure below shows the formation of nanofluids: 


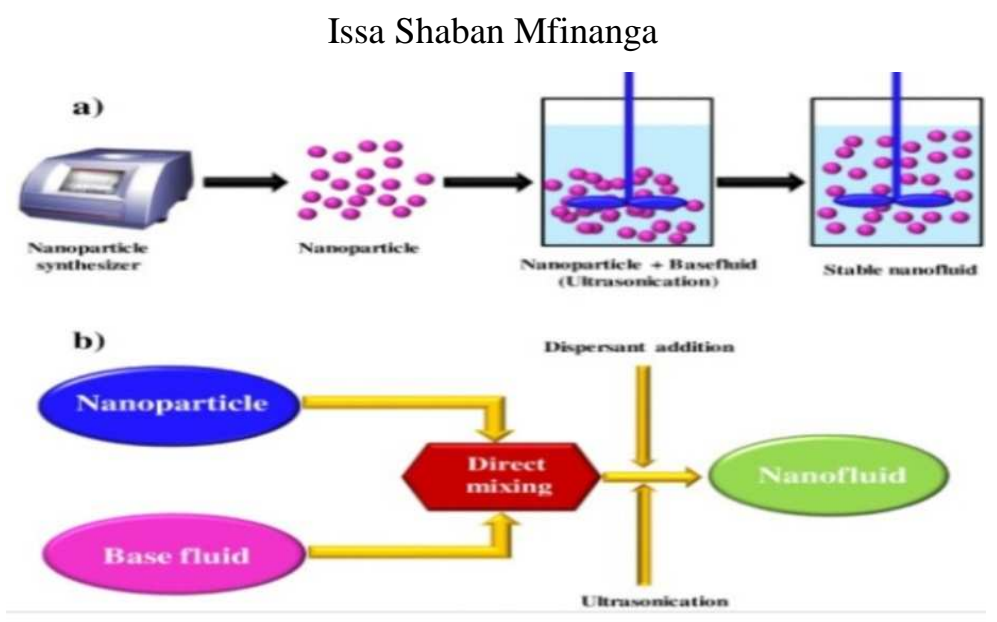

Figure 1: Nanofluid formation

Mkwizu and Makinde [1] in 2014 investigated on the entropy generation in a variable viscosity channel flow of Nano fluids with convective cooling. The results were as follows; the non-fluid viscosity and temperature profiles increases with an increase Eckert number (Ec), but decreases with an increasing Biot number (Bi). Nanoparticle concentration increases along the centreline region and decreases near the walls, with an increase in Eckert number $(\mathrm{Ec})$ and Thermophoresis parameter $(\mathrm{Nt})$. Also they observed that the skin friction increases with Eckert number (Ec) and pressure gradient (A), but decreases with Eckert number (Ec) and Thermophoresis parameter (Nt).

Anoop et al [2] in 2009 conducted an experimental investigation into convective heat transfer characteristics, in the developing region of a tube flow, with alumina-water nanofluid. They found that the enhancement of heat transfer coefficient of alumina nanofluids depended on particle sizes and the convective heat transfer coefficient of nanofluids enhanced with increasing nanoparticle concentration.

Makinde and Eegunjobi [3] in 2013 did an investigation on analysis of inherent irreversibility in a variable viscosity magneto-hydrodynamic (MHD) generalized Couette flow with permeable walls. They found that the optimal design and the efficient performance of a flow system or a thermally designed system can be improved by choosing the appropriate values of the physical parameters, and this was because there are effects towards the upper and lower moving plates.

Chen et al [4] in 2014 from the investigation they made, they found out that for a lower Brinkman number, the local Nusselt number of the nanofluid on the hot wall is greater than that of pure water and increases with an increasing nanoparticle concentration. Vice-versa was also true for higher Brinkman number. Finally, the average entropy generation number of the nanofluid was less than that of pure water.

Khanafer et al [5] in 2003 presented a theoretical analysis for buoyancy-driven heat transfer enhancement in a two- dimensional enclosure utilizing nanofluids. Abu-Nada [9] reported the application of nanofluids for heat transfer enhancement of separated flow encountered in a backward facing step.

Bianco et al [6] in 2011 investigated on an entropy generation analysis to find the optimal working condition for the given geometry under given boundary conditions, they proposed a simple analytical procedure to evaluate the entropy generation and the 
Numerical Investigation of the Effect of Parameters in Nanofluid Flows in a Channel with Navier Slip and Convective Cooling

outcomes were compared with the numerical calculations. A comparison of the resulting Nusselt numbers with experimental correlations available in literature was accomplished. They found that to minimize entropy generation, the optimal Reynolds number must be determined.

Rashidi et al [7] in 2013 conducted a study based on entropy generation in steady magneto-hydrodynamic (MHD) flow due to a rotating porous disk in a nanofluid. The main purpose of this research was to use the second law of thermodynamics efficiently in calculations of rotating fluidic systems. Also fundamental objective of the second law thermodynamics analysis had also been achieved such that the minimization of entropy in the swirling disk flow regime, when the magnetic interaction parameter, suction parameter and nanoparticle volume fraction decreased.

Ehsan et al [8] in 2011 conducted a numerical investigation on heat transfer performance and pressure drop of nanofluids flows through a straight circular pipe in a laminar flow regime and constant heat flux boundary condition. The results indicated that the particle volume concentration, Brownian motion and aspect ratio of nanoparticles similar to flow Reynolds number increase the heat transfer coefficient, while the nanoparticle diameter has an opposite effect on the heat transfer coefficient.

Jawad et al [9] in 2016 presented a study focused on the presentation of a numerical solution for copper-water nanofluid through a stretching channel with spherical and cylindrical shape nanoparticles. The analysis of nanofluid in a channel with stretching walls under slip effects was made by introducing the conservation equation of nanoparticle volume fraction into Hamilton-Crosser's nanofluid model. The study revealed that the thermal boundary layer thickness increases by increasing the solid volume fraction.

Matofali [10] in 2020 he did an investigation on the effects of navier slip and upper wall permeability of nanofluids flow with convective cooling. The mathematical model of channel flow of nanofluids (alumina or Copper as nanoparticles) was used. The study revealed that, the velocity of nanofluids decrease with increase in friction and increase in nanoparticle volume fraction causes a decrease in velocity of nanofluids, whereas the nanofluid temperature increases with Eckert number, pressure gradient parameter, time and space. Nanofluid temperature was decreasing with an increase in Reynolds number and nanoparticle volume fraction.

Mkwizu et al [11] in 2015 conducted numerical investigation into entropy generation in a transient generalized Couette flow of nanofluids with convective cooling and come with these results such that the Alumina-water nanofluid tends to flow faster than $\mathrm{Cu}$-water nanofluid, the temperature of $\mathrm{Cu}$-water nanofluid rises higher than Alumina-water nanofluid and $\mathrm{Cu}$-water nanofluid produces higher skin friction than Alumina-water nanofluid.

The Alumina-water nanofluid produces higher entropy generation rate than $\mathrm{Cu}$ water nanofluid near the lower wall, but as it approaches the upper wall, $\mathrm{Cu}$-water nanofluid produces higher entropy generation rate than Alumina-water nanofluid.

\section{Mathematical model}

The effects of Navier slip on flow of water based nanofluids containing Copper $(\mathrm{Cu})$ and Alumina $\left(\mathrm{Al}_{2} \mathrm{O}_{3}\right)$ as nanoparticles are considered. This study assumes that the lower wall 


\section{Issa Shaban Mfinanga}

doesn't move at $t>0$ where by the upper wall moves and exchange heat with ambient surrounding following the Newton's law of cooling. Take a Cartesian coordinate system $(x, y)$ where $x$ lies along the flow direction, $y$ is the distance measured in the normal direction as shown in the figure 4 below;

$$
\begin{array}{crrrl}
u=0, & -k_{n f} \frac{\partial T}{\partial y} & =h\left(T-T_{w}\right), & y=a & \\
\mu_{f} \frac{\partial u}{\partial y}=-\beta u, & T & =T_{w} & y & =0
\end{array}
$$

Figure 2: Schematic diagram of the problem under consideration

The governing equations for the nanofluids momentum and energy in one dimension with assumption above, can be written as follows

$$
\begin{aligned}
& \frac{\partial u}{\partial x}=-\frac{1}{\rho_{n f}} \frac{\partial P}{\partial x}+\frac{\mu_{n f}}{\rho_{n f}} \frac{\partial^{2} u}{\partial y^{2}}-\frac{\sigma_{w \beta_{0}}}{\rho_{f}} \\
& \frac{\partial T}{\partial x}=\alpha_{n f} \frac{\partial^{2} T}{\partial y^{2}}+\frac{\alpha_{n f} \mu_{n f}}{k_{n f}}\left[\frac{\partial u}{\partial y}\right]^{2}
\end{aligned}
$$

where $u$ is the nanofluid velocity in the $\mathrm{x}$-direction, $\mathrm{T}$ is the temperature of the nanofluid, $\mathrm{P}$ is the nanofluid pressure, $t$ is the time, $a$ is the channel half width, $T_{w}$ is the ambient temperature, $\mu_{n f}$ is the dynamic viscosity, $K_{n f}$ is the nanofluid thermal conductivity, $\rho_{n f}$ is the density of the nanofluid, and $\alpha_{n f}$ is the thermal diffusivity of the nanofluid which are given below as (Abu-Nada 2008; Makinde 2012, 2013a; Bejan 1982);

$$
\begin{gathered}
\mu_{n f}=\frac{\mu_{f}}{(1-\emptyset)^{2 \cdot 5}}, \\
\rho_{n f}=(1-\varphi) \rho_{f}+\varphi \rho_{s}, \\
\alpha_{n f}=\frac{k_{n f}}{\left(p c_{p}\right)_{n f}}, \quad \tau=\frac{\left(p c_{p}\right)_{s}}{\left(p c_{p}\right)_{f},} \\
\frac{k_{n f}}{k_{f}}=\frac{\left(k_{s}-2 k_{f}\right)-2 \varphi\left(k_{f-k_{s}}\right)}{\left(k_{s}+2 k_{f}\right)+\varphi\left(k_{f}-k_{s}\right)} \\
\left(p c_{p}\right)_{n f}=(1-\varphi)\left(p c_{p}\right)_{f}+\varphi\left(p c_{p}\right)_{s}
\end{gathered}
$$

The nanoparticles volume fraction is represented by $\varphi(\varphi=0$ correspond to regular fluid), $\rho_{f}$ and $\rho_{s}$ are the densities of base fluid and nanoparticle respectively, $k_{f}$ and $k_{s}$ are the Thermal conductivities of the base fluid and nanoparticles respectively, 
Numerical Investigation of the Effect of Parameters in Nanofluid Flows in a Channel with Navier Slip and Convective Cooling

$\left(\rho c_{p}\right)_{f}$ and $\left(\rho c_{p}\right)_{s}$ are the Heat capacities of the base fluid and nanoparticles respectively. The initial and boundary conditions are as follows;

$U(y, 0)=0, \quad T(y, 0)=0$

$$
\begin{gathered}
u(0, t)=0, T(0, t)=T_{w} \\
\mu_{f} \frac{\partial u}{\partial y}(0, t)=-\beta u(0, t) \\
-k_{n f} \frac{\partial T}{\partial y}(a, t)=h\left(T(a, t)-T_{w}\right)
\end{gathered}
$$

where the $T_{w}$ is ambient temperature of the wall.

Table 1 below presents thermo physical properties of water, copper and alumina at the reference temperature.

Table 1: Thermophysical properties of the fluid phase (water) and nanoparticles

\begin{tabular}{|c|l|l|l|}
\hline $\begin{array}{l}\text { Physical } \\
\text { Properties }\end{array}$ & $\begin{array}{l}\text { Fluid } \\
\text { Phase(Water) }\end{array}$ & $\operatorname{Copper}\left(\boldsymbol{C}_{\boldsymbol{u}}\right)$ & Alumina $\left(\boldsymbol{A l}_{\mathbf{2}} \boldsymbol{O}_{\mathbf{3}}\right)$ \\
\hline$C_{P}(\mathrm{~J} / \mathrm{kgK})$ & 4179 & 385 & 765 \\
\hline$\rho\left(\mathrm{kg} / \mathrm{m}^{3}\right)$ & 997.1 & 8933 & 3970 \\
\hline $\mathrm{k}(\mathrm{W} / \mathrm{mK})$ & 0.613 & 401 & 40 \\
\hline
\end{tabular}

We introduce the dimensionless variables and parameters as follows:

$$
\begin{aligned}
\theta & =\frac{T-T_{w}}{T_{w}}, \mathrm{~W}=\frac{u}{U}, \bar{t}=\frac{t U}{a}, v_{f}=\frac{\mu_{f}}{\rho_{f}}, \bar{P}=\frac{P_{a}}{\mu_{f U}}, A=-\frac{\overline{\partial P}}{\partial X}, \quad X=\frac{x}{a}, \eta=\frac{y}{a}, P_{r}=\frac{\mu_{f} c_{p f}}{k_{f}}, \\
E_{c} & =\frac{U^{2}}{c_{\rho f} T_{w}}, \tau=\frac{\left(\rho c_{\rho}\right)_{s}}{\left(\rho c_{\rho}\right)_{f}}, m=\frac{\left(k_{s}+2 k_{f}\right)+\varphi\left(k_{f}-k_{s}\right)}{\left(k_{s}+2 k_{f}\right)-\varphi\left(k_{f}-k_{s}\right)}, R_{e}=\frac{U_{a}}{v_{f}},
\end{aligned}
$$

The dimensionless governing equations together with the appropriate initial and boundary conditions can be written as;

$$
\begin{aligned}
& \frac{\partial W}{\partial t}=\frac{A}{R_{e}\left(1-\varphi+\frac{\varphi \rho_{s}}{\rho_{f}}\right)}+\frac{1}{R_{e}\left(1-\varphi+\rho_{s} / \rho_{f}\right)(1-\varphi)^{2.5}} \frac{\partial^{2} W}{\partial \eta^{2}}, \\
& \frac{\partial \theta}{\partial t}=\frac{1}{m P_{r} R_{e}(1-\varphi+\varphi \tau)} \frac{\partial^{2} \theta}{\partial \eta^{2}}+\frac{E_{c}}{R_{e}(1-\varphi+\varphi \tau)(1-\varphi)^{2.5}}\left(\frac{\partial W}{\partial \eta}\right)^{2},
\end{aligned}
$$

With initial and boundary conditions;

$$
\begin{gathered}
w(\eta, 0)=\theta(\eta, 0)=0 \\
W(0, t)=\theta(0, t)=0 \\
\frac{\partial w}{\partial \eta}(0, t)=-\frac{\beta a}{\mu_{f}} w(0, t) \\
\frac{\partial \theta}{\partial \eta}(1, t)=-m B i \theta(1, t)
\end{gathered}
$$

\section{Numerical procedure}

Using a discretization finite difference method, the nonlinear initial boundary value problem (IBVP) in equation (8) and (9) can be solved numerically. We use partition of 
the spatial interval $0 \leq \eta \leq 2$ into $N$ equal parts and define the grid size $\Delta \eta=\frac{1}{N}$ and the grid point $\eta_{i}=(i-1) \Delta \eta$ and $1 \leq i \leq N+1$, the first and second partial differential equations were discretized using the central difference method. Let $W_{i}(t)$ and $\theta_{i}(t)$ be the approximation of $W\left(\eta_{i}, t\right)$ and $\theta\left(\eta_{i}, t\right)$ then the semi-discrete system for the problem becomes;

$$
\begin{gathered}
\frac{d W}{d X}=\frac{A}{(1-\theta)^{2.5}\left((1-\theta)+\varphi^{\rho_{s}} / \rho_{f}\right)}+\frac{1}{(1-\theta)^{2.5}\left((1-\theta)+\varphi^{\rho_{s}} / \rho_{f}\right)} \frac{W_{i+1}-2 W_{i}+W_{i-1}}{(\Delta \eta)^{2}}, \\
\frac{d \theta}{d X}=\frac{\mu_{f}}{m P_{r}(1-\theta+\theta \tau)}\left(\frac{\theta_{i+1}-2 \theta_{i}+\theta_{i-1}}{(\Delta \eta)^{2}}\right)+\frac{E_{c}}{R_{e}(1-\theta+\theta \tau)(1-\theta)^{2.5}}\left(\frac{W_{i+1}-W_{i-1}}{2 \Delta \eta}\right)^{2},
\end{gathered}
$$

Equations (14) and (15) are systems of first order ordinary differential equations with known initial conditions and boundary condition. These can be easily solved iteratively using Runge-Kutta Fehlberg integration technique implemented on computer using Matlab.

\section{Results and discussion}

In this study, pure water has been considered as the base fluid and the nanoparticles used are copper $(\mathrm{Cu})$ and alumina (Al2O3). The Prandtl number of the base fluid (water) is kept constant at 6.2 and the effect of solid volume fraction is investigated in the range of $0 \leq \phi \leq 0.3$. Numerical solution for the representative velocity field and temperature field has been carried out by assigning some arbitrary chosen specific values to various thermophysical parameters controlling the flow system (see figure 4.3- 4.11). The detailed discussion and graphical representation of the results of above equations are reported in this section.

\subsection{Effects of parameter variation on velocity profiles}

In this section, nanofluid velocity profiles are illustrated and effects of various parameters on nanofluid velocity are presented. Figure 3 and 4 depicts the variation of velocity profile of two different nanofluids for a given set of parameter values as space and time increases. 
Numerical Investigation of the Effect of Parameters in Nanofluid Flows in a Channel with Navier Slip and Convective Cooling

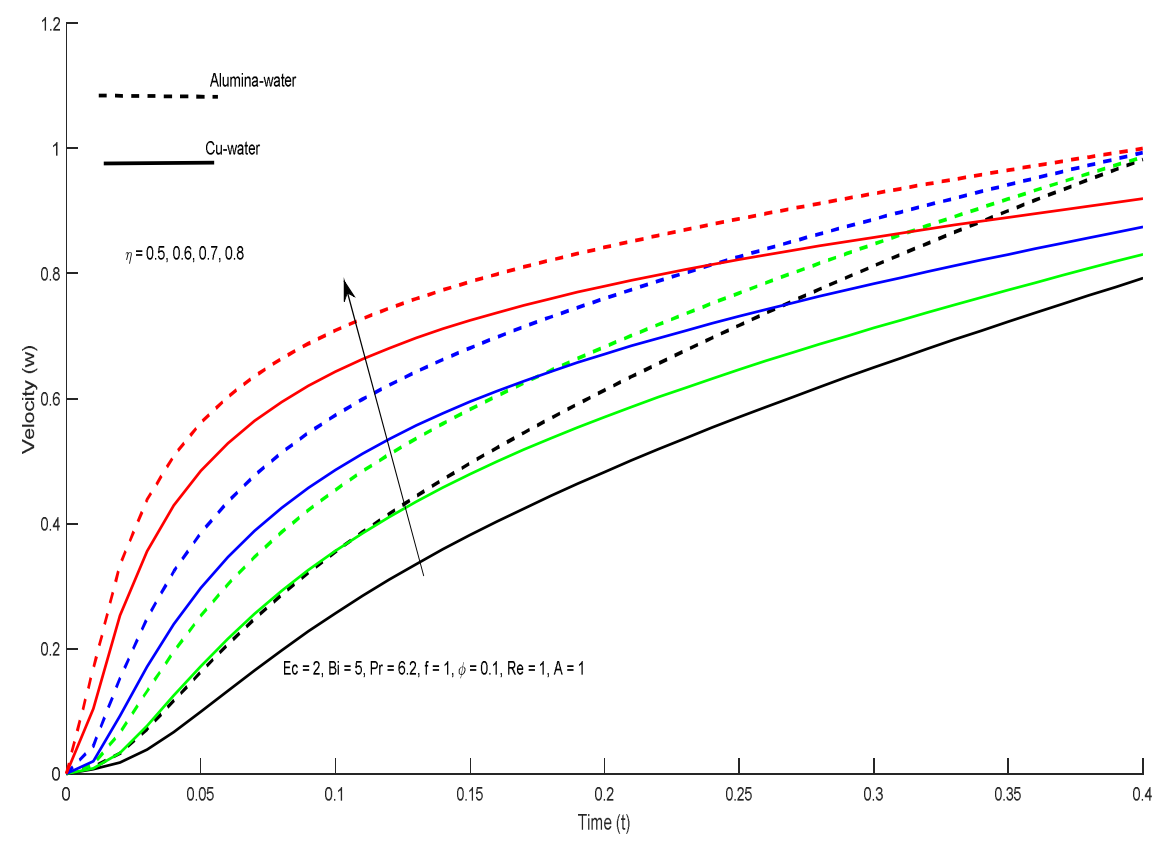

Figure 3: Nanofluid velocity profile with increasing time (t)

In figure 3 it is observed that the velocity increases with the increase of time for a given set of parameter values, as the space increases the nanofluid velocities decreases, Alumina-water nanofluid tends to flow faster at the left plate than copper-water nanofluids as time increases. This result may be due to the low density of alumina nanoparticle as compared to copper nanoparticle.

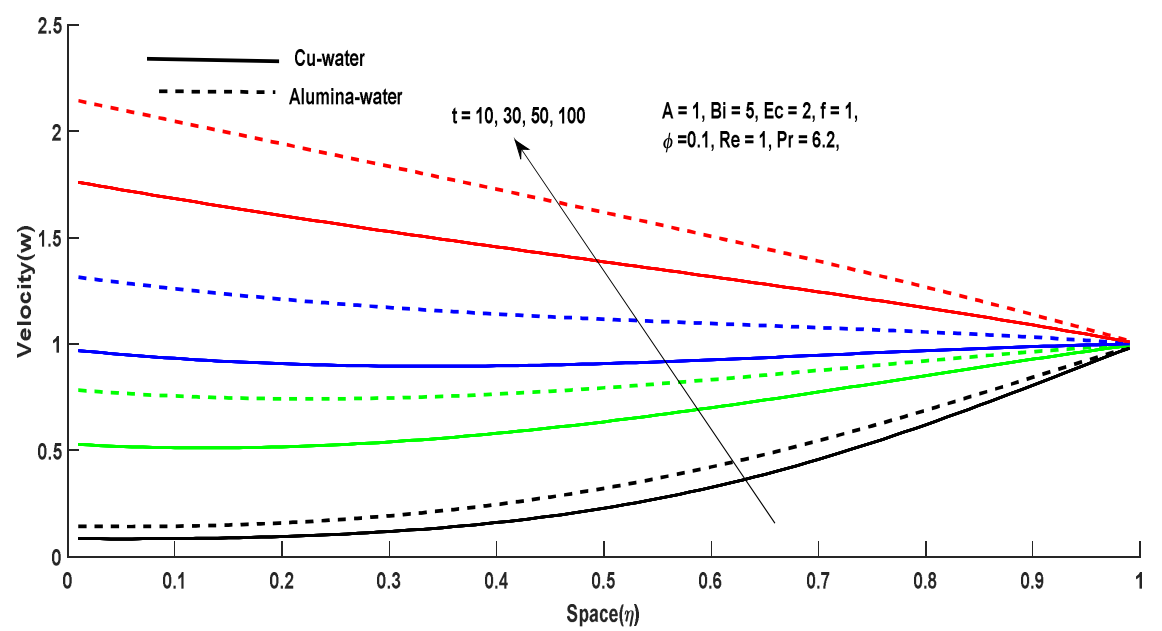

Figure 4: Nanofluid velocity profile with increasing space $(\eta)$ 


\section{Issa Shaban Mfinanga}

In figure 4 , it can be noticed that the nanofluid velocity increases with time as well as space, the nanofluid velocity is maximum at the wall of the lower plate and minimum at the wall of the upper moving plate, Alumina-water nanofluid tends to flow faster than copper-water nanofluids as time increases. This result may be due to the high density of copper nanoparticle as compared to Alumina nanoparticle.

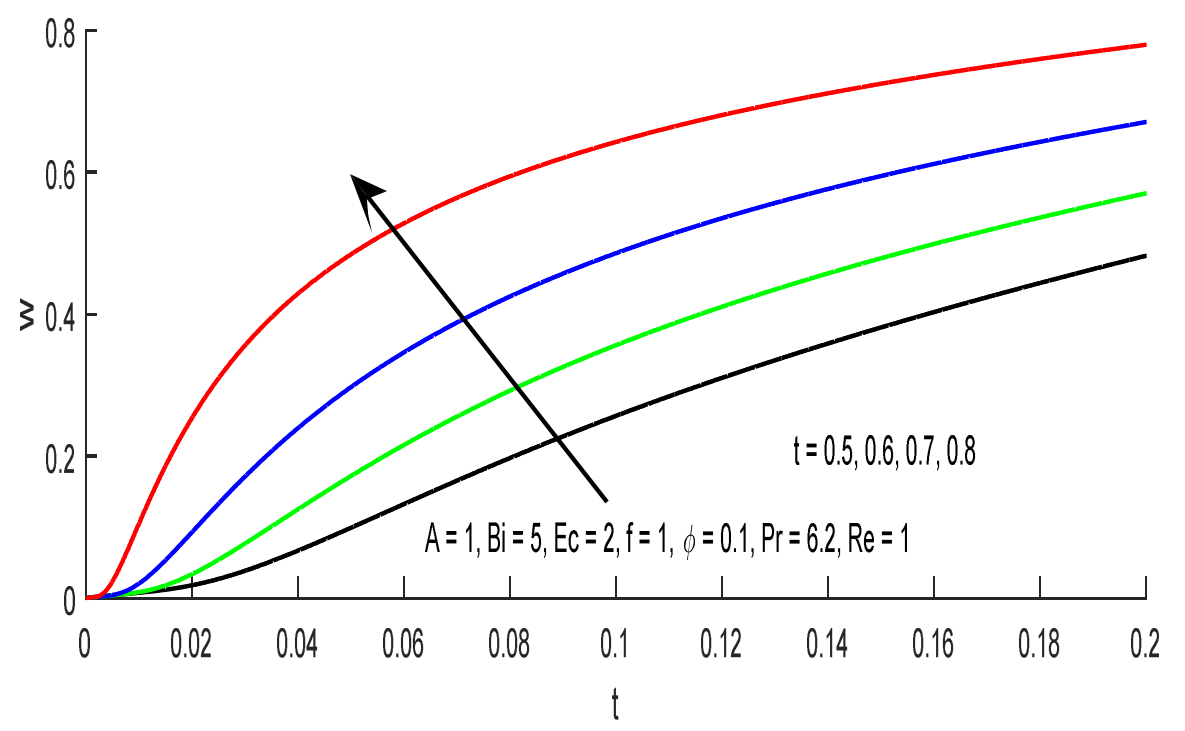

Figure 5: Nanofluid velocity profile with increasing (t)

From figure 5, it can be observed that an increase in time (t) causes an increase in velocity. This result may be due to the fact that the fluid flow doesn't have nanoparticles such that $\mathrm{f}=1$.

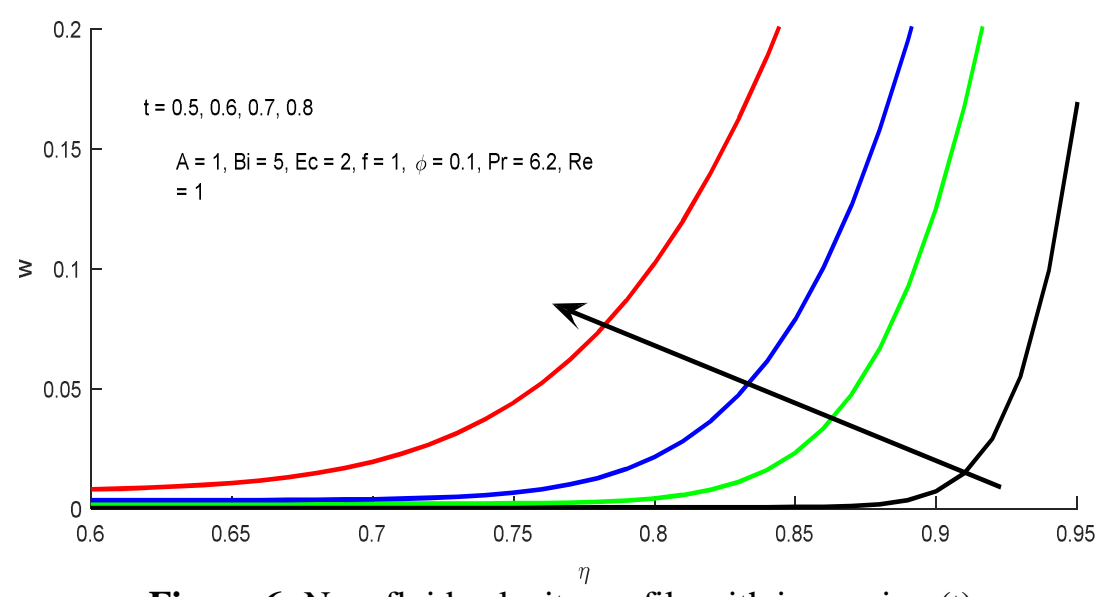

Figure 6: Nanofluid velocity profile with increasing (t)

From figure 6 , it can be observed that an increase in time span (t) causes an increase in velocity from $(\eta) 0.6$ to 0.95 . Also the fluid velocity increase slowly from the lower plate and increasing faster as it approaches the upper plate. This result may be due to the factor that the fluid flow doesn't have nanoparticles such that $f=1$ and the velocity of the plate 
Numerical Investigation of the Effect of Parameters in Nanofluid Flows in a Channel with Navier Slip and Convective Cooling

tends to increase the velocity of the water flow, such that water move with the resultant velocity.

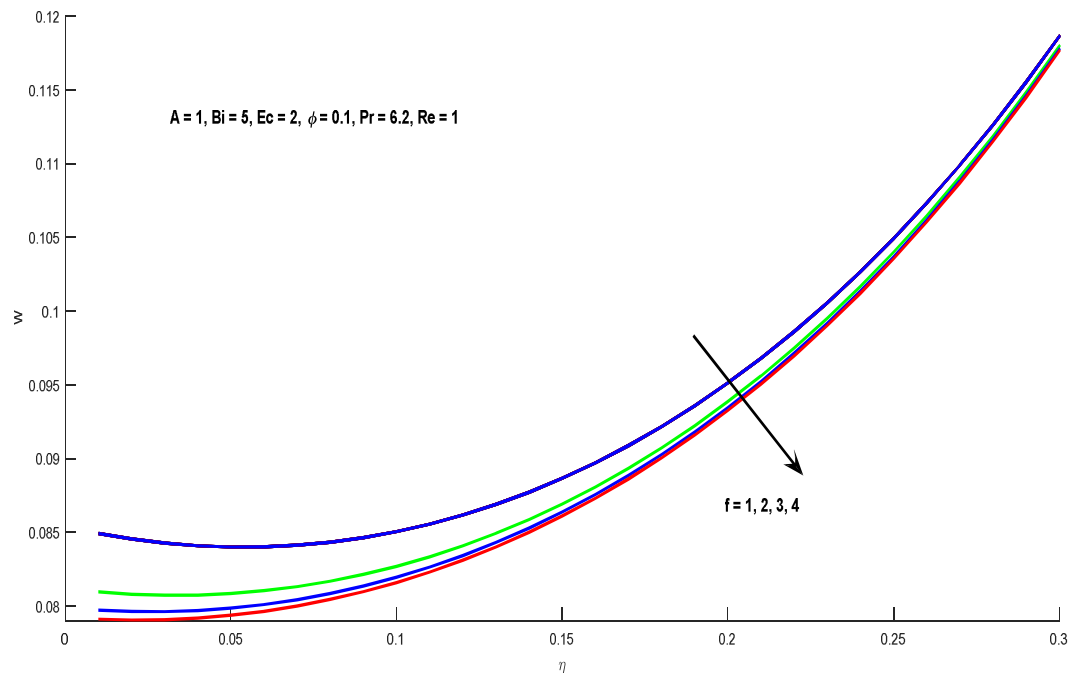

Figure 7: Nanofluid velocity profiles with increasing (f)

Figure 7, shows that, an increase in nanoparticle impurities (f) causes decrease in velocity. This result may be due to the density and the viscosity of the nanofluid which increases with an increasing nanoparticles impurity. Again the observation show that the nanofluid velocity increases to the maximum at the moving upper plate of the channel flow.

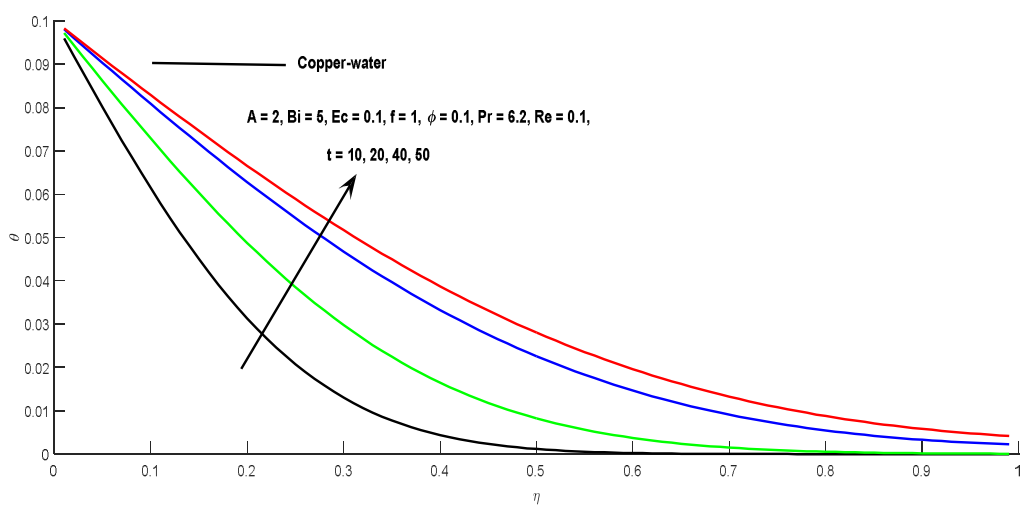

Figure 8: Nanofluid temperature profiles with increasing space $(\eta)$

Figure 8 revelled that an increase in space $(\eta)$ causes an increase in temperature. Also there is high temperature when the space is 0 and low temperature at the upper plate when the space increases above 0 . This result may be due the factor that temperature increase when the space of the channel flow is small and the temperature decrease when the space is large. 


\section{Issa Shaban Mfinanga}

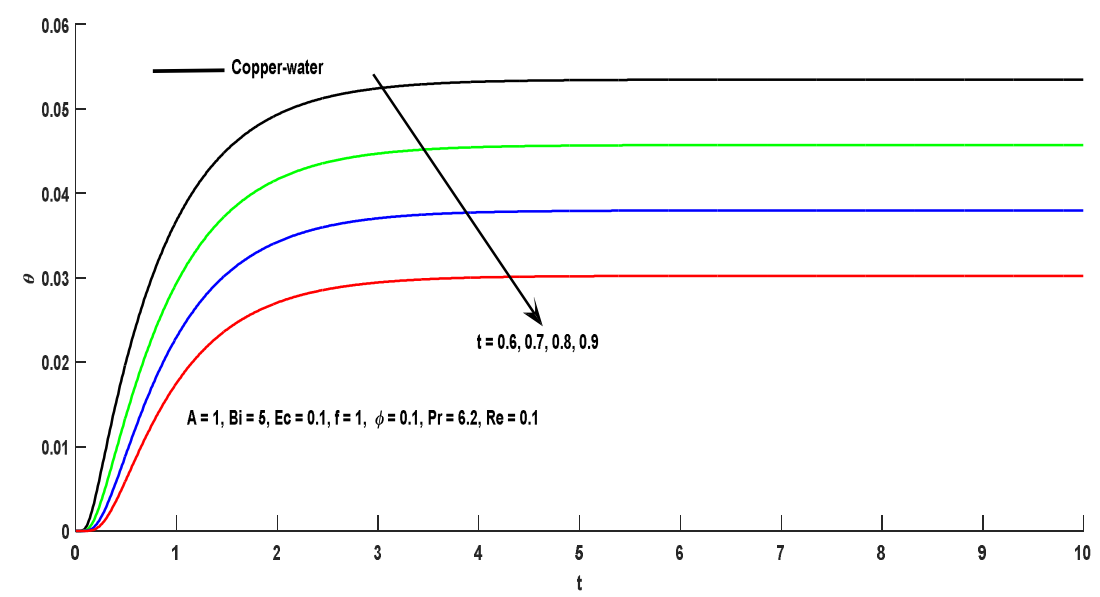

Figure 9: Temperature profile with the increase in time $(\mathrm{t})$

Figure 9, shows that, an increase in time (t) causes the decrease in temperature. This result may be due to the convective cooling due to heat loss to the ambient surrounding from the channel walls. Moreover, it is observed that the temperature decreases with the increases of time.

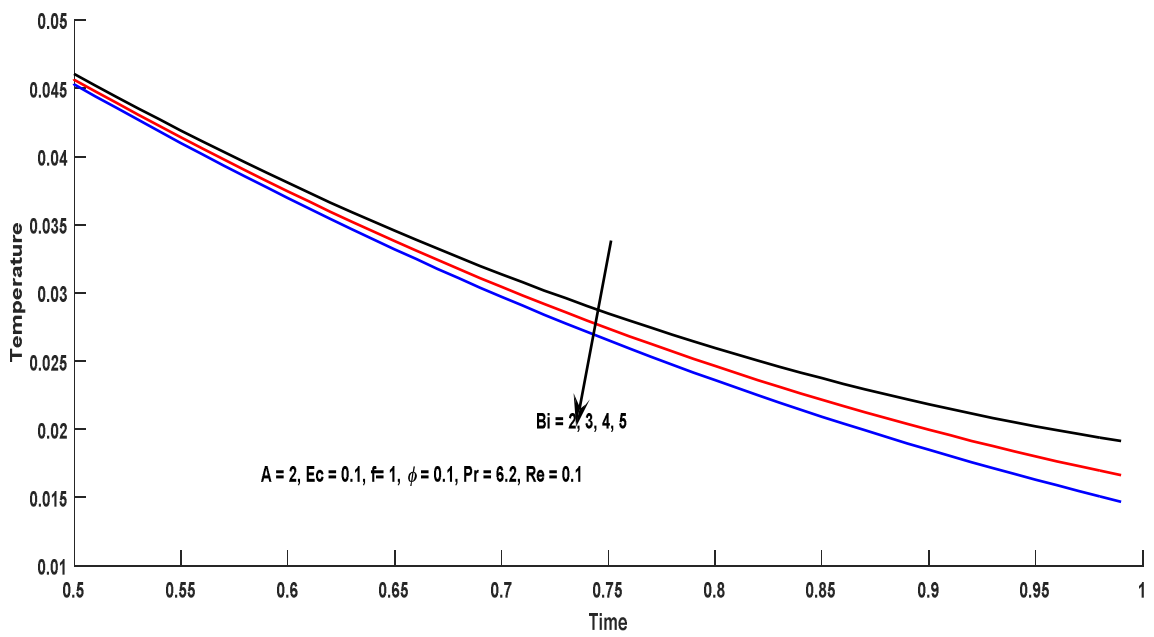

Figure 10: Temperature profile with the increase in Biot number (Bi)

The effects of the Biot number Bi on temperature profiles is illustrated in Figure 10. It is noted that the nanofluid temperature falls as the Biot number increases since an increase in Biot number indicates a rise in convective cooling due to heat loss to the ambient surrounding from the channel walls. 
Numerical Investigation of the Effect of Parameters in Nanofluid Flows in a Channel
with Navier Slip and Convective Cooling

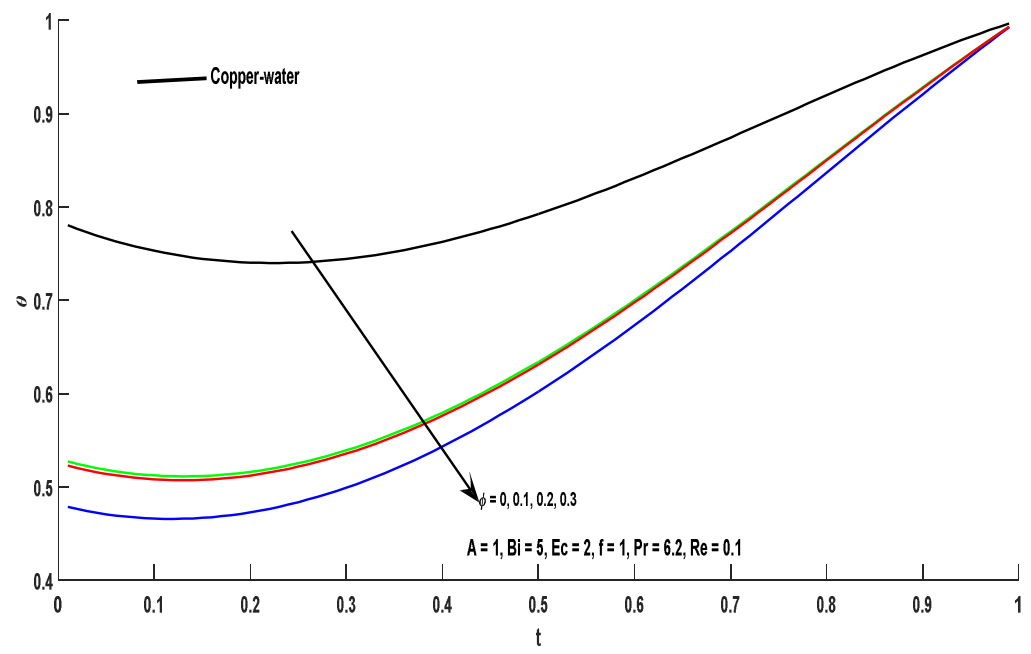

Figure 11: The temperature profile with the increase in $\left(^{\phi}\right)$

Figure 11, shows that there is a decrease in temperature when there is an increase in nanoparticles to the channel flow, this may be due to the fact that nanoparticles introduced into the channel flow absorb heat and hence reduce temperature. Not only that but also at the lower plate there is low temperature compared to the upper plate, this effect may be due to the factor that there is the frictional force between the upper plate and the moving nanoparticles at the lower plate.

\section{Conclusion}

Computational model and thermodynamic analysis of the Effect of Navier slip and Parameters in nanofluid containing Copper $(\mathrm{Cu})$ and Alumina $\left(\mathrm{Al}_{2} \mathrm{O}_{3}\right)$ as nanoparticles is presented. Using a sem-discretization method together with Runge-Kutta Fehlberg integration scheme the transient problem is numerically tackled. Some of the results obtained are as follows:

The Alumina-water nanofluid tends to flow faster than $\mathrm{Cu}$-water nanofluid. For both Aluminawater and $\mathrm{Cu}$-water nanofluids their velocity increases with time until they reach their steady state, but Alumina -water reaches its steady state earlier than $\mathrm{Cu}$-water. The nanofluid velocity increases with Reynolds number (Re), pressure gradient, (A) but decreases with an increase of nanoparticle volume fraction $\phi$. The nanofluid velocity is maximum at the lower plate of the channel flow and minimum at the wall of the upper plate as the space increases. The temperature of Alumina-water nanofluids rises faster than that of $\mathrm{Cu}$-water nanofluids. The nanofluid temperature increases with Eckert number $(\mathrm{Ec})$ and space increases, but decrease in nanofluid temperature is noticed with an increase of Biot number (Bi) and nanoparticle volume fraction $(\phi)$.

\section{REFERENCES}

1. M.H.Mkwizu and O.D.Makinde, Entropy generation in avariable viscosity channel flow of nanofluids with convective cooling, Comptes Rendus Mecanique, 343 (2014), $38-56$. 


\section{Issa Shaban Mfinanga}

2. K.B. Anoop, T.Sundararajan, S.K.Das, Effect of particle size on the convective heat transfer in nanofluid in the developing region, Int. J. Heat and Mass Transfer, 52 (2009) 2189- 2195.

3. O.D.Makinde and A.S.Eegunjobi, Analysis of inherent irreversibility in a variable viscosity MHD generalized couette flow with permeable wall, Journal of Thermal Science and Technology, 8(1) (2013) 240-254.

4. C.Chen, B.Chen and C.Liu, Heat transfer and entropy generation in fully-developed mixed convection nanofluid flow in vertical channel, International Journal of Heat and Mass Transfer, 79 (2014 ) 750-758.

5. K.Khanafer, K.Vafai and M.Lightstone, Buoyancy- driven heat transfer enhancement in a two-dimensional enclosure utilizing nanofluids, Int. J. Heat Mass Transfer, 46 (2003) 3639-3653.

6. V.Bianco, S.Nardini and O.Manca, Enhancement of heat transfer and entropy generation analysis of nanofluids turbulent convection flow in square section tubes, Nanoscale Research Letters, 6 (1) (2011) 252.

7. M.M.Rashidi, S.Abelman and N.F.Mehr, Entropy generation in steady MHD flow due to a rotating porous disk in a nanofluid, International Journal of Heat and Mass Transfer, 62 (2013) 515-525.

8. E.Ehsan, et al. Numerical investigation of effective parameters in convective heat transfer of nanofluids flowing under a laminar flow regime, International Journal of Heat and Mass Transfer, 54(19) (2011) 1-34.

9. R.Jawad et al., Numerical investigation of copper-water (cu-water) nanofluid with different shapes of nanoparticles in a channel with stretching wall: slip effect, Mathematical and Computational Applications, 21(4) (2016) 1-15.

10. A.Matofali, Numerical investigation on the effects of navier slip and upper wall permeability of nanofluids flow with convective cooling, International Journal of Modern Trends in Engineering and Research, 07 (2020) 39 - 52.

11. M.H.Mkwizu, O.D.Makinde and Y.Nkansah-Gyekye, Numerical investigation into entropy generation in a transient generalized Couette flow of nanofluids with convective cooling, Sadhana, 40 (2015) 2073 - 2093. 